\title{
SOME EXPONENTIAL OPERATOR INEQUALITIES
}

\author{
MITSURU UCHIYAMA
}

Abstract. We will simply show Ando's exponential inequality by making use of an approximation method and Furuta inequality, and then we will give some results about exponential inequalities.

Mathematics subject classification (1991): 47A63.

Key words and phrases: order of selfadjoint operators, Furuta inequality, norm derivative.

\section{REFERENCES}

[1] T. ANDO, On some operator inequalities, Math. Ann., 279 (1987) 157-159.

[2] M. FUJII, T. FURUTA, E. KAMEI, Furuta's inequality and its application to Ando's theorem, Linear Algebra and its application, 179 (1993) 161-169.

[3] T. FURUTA, Applications of order preserving operator inequalities, Operator Theory: Advances and Applications, 59 (1992) 180-190.

[4] T. FurutA, $A \geqslant B \geqslant 0$ assures $\left(B^{r} A^{p} B^{r}\right)^{1 / q} \geqslant B^{(p+2 r) / q}$ for $r \geqslant 0, p \geqslant 0, q \geqslant 1$ with $(1+2 r) q \geqslant p+2 r$, Proc. A.M.S., 101 (1987) 85-88.

[5] T. FuRUTA, An elementary proof of an order preserving inequality, Proc. Japan Acad. 65, ser. A (1989) 126.

[6] K. TAnahashi, Best possibility of the Furuta inequality, Proc. Amer. Math. Soc., 124 (1996) 141-146. 